\title{
Who Uses Virtual Wardrobes? Investigating the Role of Consumer Traits in the Intention to Adopt Virtual Wardrobes
}

\author{
Haeun Bang * and Jin Su
}

Citation: Bang, H.; Su, J. Who Uses Virtual Wardrobes? Investigating the Role of Consumer Traits in the Intention to Adopt Virtual Wardrobes. Sustainability 2022, 14, 1209. https:// doi.org/10.3390/su14031209

Academic Editors: Stacy H. Lee, Seoha Min and Hyo Jung (Julie) Chang

Received: 21 December 2021

Accepted: 19 January 2022

Published: 21 January 2022

Publisher's Note: MDPI stays neutral with regard to jurisdictional claims in published maps and institutional affiliations.

Copyright: (C) 2022 by the authors. Licensee MDPI, Basel, Switzerland. This article is an open access article distributed under the terms and conditions of the Creative Commons Attribution (CC BY) license (https:// creativecommons.org/licenses/by/ $4.0 /)$.

\author{
Department of Consumer, Apparel, and Retail Studies, Bryan School of Business and Economics, \\ University of North Carolina at Greensboro, Greensboro, NC 27412,USA; j_su@uncg.edu \\ * Correspondence: h_bang2@uncg.edu
}

\begin{abstract}
Over-consumption by consumers is a significant challenge to sustainability. Technology, such as that of virtual wardrobes, can suggest options that may reduce excessive consumption. A virtual wardrobe is a service that allows users to create and manage their wardrobes digitally. It also helps users to realize what they have in their wardrobes and can recommend appropriate styles of clothing for the users based on an analysis of the wardrobe. From the perspective of consumer characteristics, this research investigates what motivates consumers to adopt and use virtual wardrobes and proposes marketing strategies for addressing these behaviors. Fishbein's attitude theory was used as a theoretical framework. By surveying 265 U.S. college students and using structural equation modeling analysis, the study shows that consumers' socially responsible consumption behavior and personal innovativeness in information technology positively affect their attitude toward virtual wardrobes, which, in turn, increases their intention to use virtual wardrobes. However, their personal shopping value and fashion involvement have no significant impacts on consumers' attitudes toward virtual wardrobes. The findings indicate that marketers of virtual wardrobes should highlight social responsibility and technological innovation in product and service promotions. By gaining insight into their wardrobes, consumers can be more strategic about clothing consumption, use, and disposal.
\end{abstract}

Keywords: sustainability; digital fashion; consumer trait; apparel; virtual wardrobe; wardrobe management; personal shopping value; fashion involvement; socially responsible; personal innovativeness in information technology

\section{Introduction}

Consumers who own, build, and manage their wardrobes have a powerful influence on the environment, society, and economy. They decide when to purchase new clothing items, what to buy, and how many are needed. Therefore, purchasing is a significantly critical phase due to its strong connection to the other phases of the product life cycle [1]. In this aspect, a personal wardrobe plays an important role in this decision-making process. According to a survey of 1000 women in the U.S. conducted by Closetmaid in 2016 [2], $25 \%$ of the respondents felt that their wardrobes were unorganized; $44 \%$ of these women said that they could not find a clothing item in their wardrobes at least once a month due to disorganization, and about $61 \%$ of them usually decided to purchase something new instead of finding the clothing items that they already had in their wardrobes. Another statistic of 5200 U.S. participants reported by Statista [3] showed that women in the U.S. owned 164 clothing items in their wardrobes on average, but approximately 41 items of clothing (25\%) were not worn by them. Bye and McKinney [4] investigated reasons for keeping clothes that do not fit. They surveyed 46 women and found that $37 \%$ of these women had one to ten clothing items that they could not wear because they did not fit, $17 \%$ had 11 to 20 , and $15 \%$ had 21 to 50 unwearable items. They even felt difficulty in coordinating their clothes within a limited time in the morning [5] and in selecting the 
right or key items of clothing for the right occasion from a large personal collection [6,7]. These findings show that consumers are overwhelmed by clothes in their disorganized wardrobes, and it leads to unnecessary and impulse consumption.

Technology, such as that of virtual wardrobes, can suggest solutions to consumers on how they can organize their wardrobes and reduce their overconsumption. A virtual wardrobe is a service based on the web that enables users to create and manage their personal wardrobes digitally [7]. This is also known as a smart closet/wardrobe [6-9], intelligent wardrobe [10], or e-wardrobe [11]. It not only allows users to digitize their actual physical wardrobes, but also sorts items based on categories or styles and recommends outfits based on factors such as the weather, season, colors, styles, events, and user emotions [12]. Moreover, it assists users in purchasing clothes that suit their wardrobes and individual styles and allows users to rent fashion items from other users through social networking $[5,6,12]$. There are several virtual wardrobe services available, including Stylebook, SmartCloset, Purple, Cladwell, Your Closet, and so on. By gaining insight into their wardrobes, consumers can be more strategic about their clothing consumption, use, and disposal [13], and fashion retailers can be more effective in their sales [11].

The purpose of this study is to examine what motivates consumers to use virtual wardrobes, which can provide helpful insights for developers and marketers of virtual wardrobe technology and services aiming to improve user adoption of virtual wardrobes. Although the potentials of utilizing a virtual wardrobe have been highlighted in previous research, there is a lack of research on virtual wardrobe consumer profiles, especially the psychographic variables that impact consumers' adoption of virtual wardrobes. Therefore, this research fills a research gap by investigating how consumer traits play a role in the use of the virtual wardrobe services and technology based on Fishbein's attitude theory [14] with a quantitative research approach. Ajzen and Fishbein [15] argued that attitudes can positively influence one's behavioral intention. Previous studies have also confirmed a positive and significant linkage between attitude and behavioral intention with a focus on technology adoption or acceptance [16-18]. The attitude theory was one of the first models that was used to study the acceptance of technology [19], and it is widely applied in multiple disciplines $[14,20]$.

This article begins with a literature review of related research and the theoretical framework of this study, specifically focusing on each personal trait of consumers that is included in the study. The research hypotheses and model are introduced based on the literature review. In the next section, the research methods are described, including the sampling and data collection methods, development of the research stimulus, and summary of the research sample. In the following sections, the results of the statistical analysis of the structural equation modeling are shared, and the results are discussed. Finally, the conclusions address this study's theoretical and managerial implications, limitations, and the future research plans.

\section{Literature Review and Theoretical Framework}

\subsection{Related Work and Rationale for Research}

Recently, advanced technologies have made significant and dramatic shifts in various parts of the industry. The COVID-19 pandemic has accelerated these shifts, and the role of technologies in retail has become more and more important [21,22]. Fashion is an active sector that can be influenced by digital improvement, and at the same time, it can influence the lifestyles of individuals [23]. Several research studies examined virtual wardrobes, which are a digital technology that can be widely used in the apparel industry. Most of them, however, focused on developing conceptual designs [8,24], systems [5,6,25], or applications [26] rather than investigating the motivations of adopting and using these technologies from the consumers' perspective. One recent study conducted by Perry [12] examined what factors influence the adoption intentions of consumers for smart wardrobes. It developed a research model by adopting the technology acceptance model (TAM). 
Although Perry's [12] study provided significant insights into what factors influence consumer intention to use virtual wardrobe technology, the demographics of their research participants varied widely, which can affect the attitudes and behavioral intentions. Previous research found that socio-demographic characteristics such as age, gender, education, and income are variables that can influence attitudes and behavioral intentions, especially in terms of sustainable consumption [27]. Moreover, the variables used in their study were more related to the features of the product/service itself rather than consumers' personal traits. To fill the research gap, therefore, our study used variables that are directly related to personal traits of consumers, and it surveyed research participants who shared similar socio-demographic characteristics to minimize the impact of socio-demographics.

This research utilizes Fishbein's attitude theory [14] as a theoretical framework. According to Fishbein and Ajzen [14], the definition of attitude is an individual's general reaction or sentiment, including both positive and negative, about performing a certain desired behavior. The theory of Fishbein indicates a causal relationship between three cognitive variables: beliefs, attitudes, and intentions. In these relationships, attitude plays a role that shapes a person's prominent beliefs at a given time [14]. This study focuses on consumers' personal attitudes toward virtual wardrobes and how the attitudes influence their intention to adopt and use this service. This research proposes that four traits of consumers-personal shopping values, fashion involvement, socially responsible consumer behavior, and personal innovativeness in information technology-impact individuals' attitudes toward virtual wardrobe technology and their intentions to use it.

\subsection{Personal Shopping Value}

Personal shopping value is one of the most critical and influential factors in understanding consumer behavior $[28,29]$. Perceived value is "the consumer's overall assessment of the utility of a product based on perceptions of what is received and what is given" [28] (p. 14). Anything that consumers gain-e.g., quality, benefits, worth, utilities, etc.-is considered as what they receive; anything for which they need to pay-e.g., price, sacrifice, etc.-in order to acquire the possible benefits is considered as what is given [30]. However, researchers have started to focus on personal shopping value with the aspects of shopping experience value [31] and shopping trip value [29,32] rather than emphasizing the tradeoff between what is earned versus what is given [33]. The personal shopping value defined by Babin et al. [32] is the perceived emotional and psychological value acquired from engaging in a purchasing experience. It represents consumer perceptions of a holistic shopping experience that includes both hedonic and utilitarian shopping value [32].

According to Batra and Ahtola [34], consumer attitude inherently includes bidimensional components because the purpose of performing consumption behaviors is to achieve “(1) consummatory affective (hedonic) gratification (from sensory attributes), and (2) instrumental, utilitarian reasons concerned with expectations of consequences" (p. 159). Both emotional and quality values that are perceived by users can shape their commitment to a product and/or service [35].

In this study, we consider that consumer attitude toward virtual wardrobes represents an overall assessment of the service utility of virtual wardrobes. Therefore, we propose that consumers' perception of shopping value positively influences consumers' attitude toward virtual wardrobes.

Hypothesis 1 (H1). Personal shopping value has a significant positive impact on an individual's attitude toward virtual wardrobes.

\subsection{Fashion Involvement}

To understand and examine consumers' behaviors and attitudes, involvement has been used as an important measure [36]. Involvement refers to "the degree to which a consumer considers a particular purchase decision and perceives it to be important to him/herself" [37] (p. 71). The level of involvement determines an individual's propensity 
to pay close attention to a product or to actively engage in particular consumption activities [38]. The definition of fashion involvement is "an individual's perceived relevance of fashion on the basis of an individual's innate needs, values, and interest" [37] (p. 71). It refers to the extent to which consumers consider fashion consumption to be central to their lives and a meaningful, engaging activity. More specifically, fashion involvement includes five dimensions of fashion-adoption-related behavior [39]: (1) fashion innovativeness and time of purchase, (2) interpersonal fashion communication, (3) fashion interest, (4) fashion knowledgeability, and (5) fashion awareness and reaction to changing fashion trends. Individuals whose fashion involvement level is higher put more value on fashionable clothing. When they evaluate a product, they do it more smoothly [40] and they are less sensitive to price. Highly involved individuals are more voluntarily and actively engaged in fashion-related activities-e.g., reading fashion news frequently or trying new fashion-related technologies [41]. Through the research of Celik and Kocaman [42], it was confirmed that fashion involvement can significantly impact technological readiness. In this aspect, this study assumed that individuals with higher fashion involvement will have a positive attitude toward virtual wardrobes. Therefore, we propose:

Hypothesis 2 (H2). Fashion involvement has a significant positive impact on attitude toward virtual wardrobes.

\subsection{Socially Responsible Consumer Behavior}

Socially responsible consumption emphasizes the importance of the role of individual attitudes and values of products or services when purchasing them [43]. Reberts [44] defined the socially responsible consumer as an individual who cares about a positive (or less negative) influence on the environment when making purchasing decisions or who expresses current social concerns and issues by using their purchasing power. Socially responsible consumer behavior (SRCB) was defined by Mohr et al. [45] as "a person basing his or her acquisition, usage, and disposition of products on a desire to minimize or eliminate any harmful effects and maximize the long-run beneficial impact on society" (p. 47). There are different stages in apparel consumption, such as "acquiring, storing, using, maintaining, and discarding" for each apparel item [46] (p. 629). Ha-Brookshire and Hodges [47] pointed out that the overall consumption process, from pre-purchase to postdisposal, should be included and evaluated. It can include other critical consumption stages besides purchasing that can impact consumers' usage, disposition, and future purchase, including product information search, storage, and post-disposal evaluations of goods and services. Thus, they defined SRCB as "the behavior of a consumer basing decisions on a desire to minimize or eliminate any harmful effects and to maximize any beneficial impacts on society in one or more consumption steps of the consumption process" [47] (p. 180). Since a virtual wardrobe allows the users to participate in multiple consumptions steps, including search, acquisition, usage, storage, disposal, and post-disposal evaluation, SRCB in this study also focuses on consumer behavior from various perspectives. Therefore, the following hypothesis is proposed:

Hypothesis 3 (H3). Socially responsible consumer behavior has a significant positive impact on attitude toward virtual wardrobes.

\subsection{Personal Innovativeness in Information Technology}

In the fields of marketing and information systems, personal innovativeness has been considered as an important personality trait that can influence the development of behavioral intentions [48]. From a psychological point of view, it is a personal characteristic that affects a person's behavior in the long term [49]. Rogers [50] insisted that most innovations that have been investigated in diffusion research have been technological innovations, and so a synonym for innovation is "technology". He defined technology as "a design for instrumental action that reduces the uncertainty in the cause-effect relationships 
involved in achieving a desired outcome" [50] (p. 139). Based on Rogers' theory of the diffusion of innovations, Agarwal and Prasad [51] defined personal innovativeness in information technology (PIIT) as an individual's will or desire to try new information technology. They described personal innovativeness as an individual trait that exists in certain individuals who have a greater tendency for risk-taking behavior [52]. Individuals with high levels of PIIT have positive perceptions of innovation in terms of advantage, ease of use, compatibility, etc., and tend to adopt and use new information technology [49]. Based upon this research stream, this study hypothesizes:

Hypothesis 4 (H4). Personal innovativeness in information technology has a significant positive impact on attitude toward virtual wardrobes.

\subsection{Attitude and Behavioral Intention}

According to Ajzen and Fishbein [53], a general notion of consistency should be considered when attempting to predict behavior from attitudes. Especially during the COVID-19 pandemic, it is critical to look into consumer attitudes in order to understand consumer behavioral intentions and acquisition decisions. Such an unexpected pandemic has changed consumer traits, emotions, beliefs, and engagement, which can directly influence their attitudes, behavioral intentions, and purchasing habits [54,55]. It is usually logical or consistent for an individual who shows a favorable attitude toward a certain object to perform favorable behaviors and not to perform unfavorable behaviors. In this context, an individual with an unfavorable attitude is expected to show unfavorable behaviors, but not to hold favorable behaviors. People with a favorable attitude are more likely to pay attention to, perceive, and accept the positive attributes of an object, while individuals with unfavorable attitudes discover its negative qualities [56]. In this sense, attitude plays an important role when investigating an individual's behavioral intention. Thus, the following hypothesis is proposed:

Hypothesis 5 (H5). Attitude toward virtual wardrobes has a significant impact on intention to use virtual wardrobes.

Given the above literature review and theoretical analysis, this paper proposes the following research model (Figure 1), which includes the five hypotheses described in the previous sections.

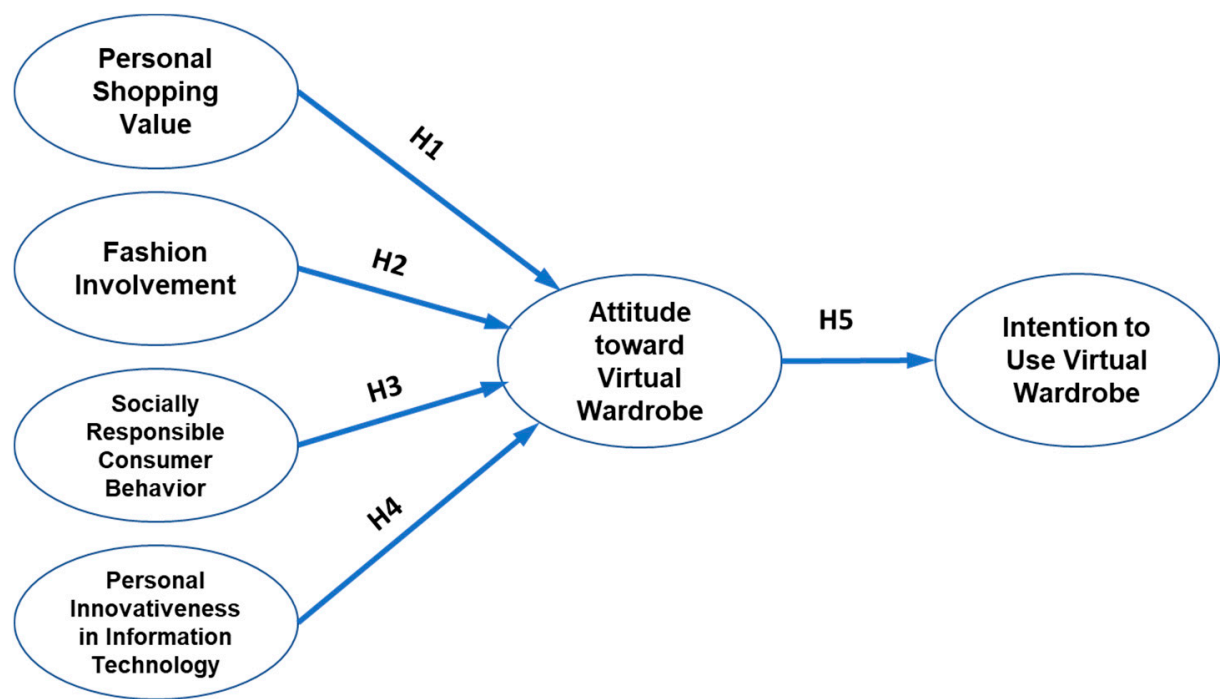

Figure 1. Research model and hypotheses. 


\section{Research Methods}

This quantitative research utilized a structured questionnaire to collect data. It was designed based on a review of previous literature and was created by using Qualtrics. Items were measured using questions on a seven-point Likert-type scale $(1=$ "strongly disagree" to 7 = "strongly agree"). The items for the constructs-personal shopping value (PSV), fashion involvement (FI), socially responsible consumer behavior (SRCB), and personal innovativeness in information technology (PIIT) - were adopted from Babin et al. [32], $\mathrm{O}^{\prime}$ Cass [57], Stephens [58], and Lu et al. [52], respectively. Table 1 includes the items used for this study.

Table 1. Measurement model results.

\begin{tabular}{|c|c|c|c|c|}
\hline Constructs and Items & $\begin{array}{l}\text { Standardized } \\
\text { Factor Loading }\end{array}$ & $t$-Value & $\begin{array}{l}\text { Composite } \\
\text { Reliability }\end{array}$ & AVE \\
\hline $\begin{array}{l}\text { Personal Shopping Value } \\
(\text { Cronbach's Alpha }=0.801)\end{array}$ & & & 0.81 & 0.59 \\
\hline $\begin{array}{c}\text { V1-Shopping is helpful to learn information about the } \\
\text { current fashion style. }\end{array}$ & 0.82 & 14.91 & & \\
\hline V2-Shopping helps me to find clothing that is suitable for me. & 0.82 & 15.00 & & \\
\hline $\begin{array}{l}\text { V3-Shopping is helpful to gain information on how to } \\
\text { coordinate clothes. }\end{array}$ & 0.66 & 11.18 & & \\
\hline $\begin{array}{c}\text { Fashion Involvement } \\
(\text { Cronbach's Alpha }=0.762)\end{array}$ & & & 0.80 & 0.57 \\
\hline V4-Clothing is important to me. & 0.89 & 16.36 & & \\
\hline V5-I consider what to wear every day. & 0.68 & 11.60 & & \\
\hline V6-I am fashion-conscious. & 0.68 & 11.64 & & \\
\hline $\begin{array}{c}\text { Socially Responsible Consumer Behavior } \\
\text { (Cronbach's Alpha }=0.778 \text { ) }\end{array}$ & & & 0.80 & 0.58 \\
\hline $\begin{array}{l}\text { V7-I think the preservation of resources should be } \\
\text { considered in clothing consumption. }\end{array}$ & 0.84 & 15.00 & & \\
\hline $\begin{array}{l}\text { V8-I think resource conservation and clothing consumption } \\
\text { are related. }\end{array}$ & 0.84 & 15.01 & & \\
\hline V9-Discarded clothing adds to our pollution problem. & 0.56 & 9.18 & & \\
\hline $\begin{array}{c}\text { Personal Innovativeness in Information Technology } \\
\text { (Cronbach's Alpha }=0.804)\end{array}$ & & & 0.83 & 0.63 \\
\hline V10-I prefer products that feature leading-edge technology. & 0.51 & 8.54 & & \\
\hline V11-People often ask me for advice on new technology. & 0.88 & 16.31 & & \\
\hline $\begin{array}{l}\text { V12-Mostly, I am the first to adopt the latest technology } \\
\text { among people around me. }\end{array}$ & 0.92 & 17.48 & & \\
\hline $\begin{array}{c}\text { Attitude toward Virtual Wardrobes } \\
\text { (Cronbach's Alpha }=0.889)\end{array}$ & & & 0.89 & 0.73 \\
\hline $\begin{array}{l}\text { V13-I think using virtual wardrobe services is (would be) a } \\
\text { good idea. }\end{array}$ & 0.83 & 16.06 & & \\
\hline $\begin{array}{l}\text { V14-I think using virtual wardrobe services is beneficial to } \\
\text { my wardrobe organization. }\end{array}$ & 0.88 & 17.61 & & \\
\hline $\begin{array}{l}\text { V15-I think using virtual wardrobe services would help } \\
\text { improve my clothing consumption habits. }\end{array}$ & 0.86 & 16.87 & & \\
\hline $\begin{array}{c}\text { Intention to Use Virtual Wardrobes } \\
(\text { Cronbach's Alpha }=0.934)\end{array}$ & & & 0.93 & 0.82 \\
\hline V16-I intend to use virtual wardrobe services. & 0.93 & 19.78 & & \\
\hline V17-I will try to use virtual wardrobe services. & 0.89 & 18.35 & & \\
\hline V18-I plan to use virtual wardrobe services in the future. & 0.90 & 18.84 & & \\
\hline
\end{tabular}

Notes: AVE = average variance extracted; all $t$-values are statistically significant at $p<0.01$; valid $n=265$.

Snowball and convenience sampling methods were used to recruit the survey participants of this study. A survey invitation was sent to professors of Apparel Design and Retail 
Merchandising at three different universities in the U.S., and with the professors' help, the online survey link was distributed to their students. Data were collected during May 2020.

To help the survey participants understand the basic concept of a virtual/digital wardrobe, a stimulus was developed with reference to Finery, as shown in Figure 2. Participants of the survey were informed of the basic concept of a virtual/digital wardrobe service and different functions integrated with this technology before they answered the questions. The description was given to them with images of the actual screenshots of Finery service as follows:

"A virtual/digital wardrobe service, which is the main topic of this research, provides convenience by transforming the user's actual wardrobe to a virtual system. It helps users to organize the clothing items in their wardrobes by various category options. Based on the analysis of frequently visited websites and clothing purchase receipts from email, the app provides various useful information. It allows users to create a personal wish list, inform sale/promotion, and suggest clothing items which should be needed for their wardrobes. It also recommends various styling ideas based on clothes they already have and influencing factors analyzed by users' social network service, i.e., Instagram. In addition to that, it helps users to dress comfortably for the climate and the occasion."

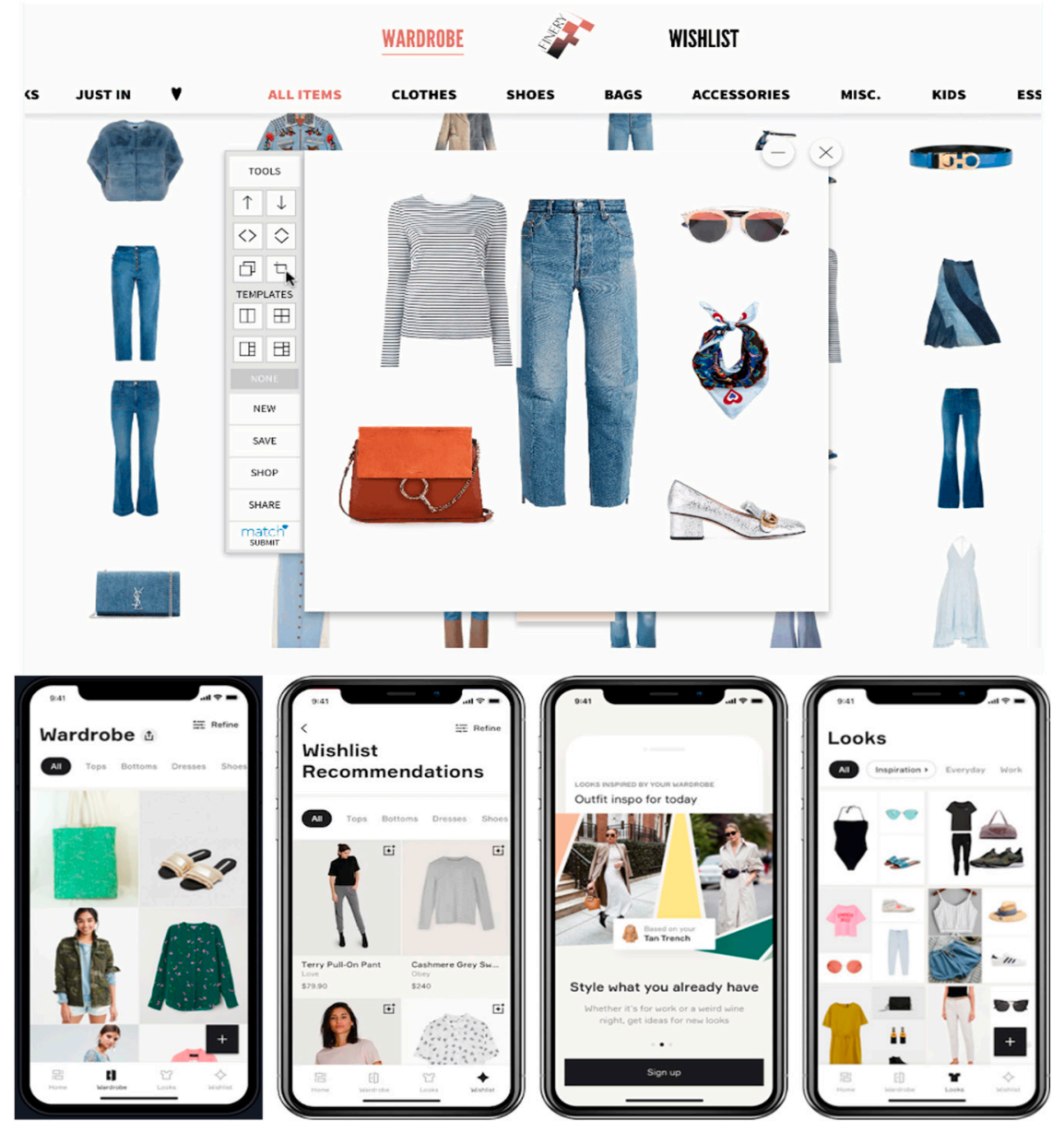

Figure 2. A virtual wardrobe service shown to survey respondents.

A total of 275 responses were collected. After reviewing the data, ten responses were removed due to consistent response patterns or incomplete responses. Finally, 265 valid responses were used for this study. A majority of the respondents (91\%) were female; $85 \%$ of the respondents were between the ages of 18 and 25, and those aged between 26 and 37 made up the second-largest segment (14\%). The respondents were $48 \%$ Caucasian, 
$27 \%$ African American, and 17\% Asian. Most of them (92\%) were single, and the average monthly spending on clothing and accessories was between USD 100 and 200 for 31\% of respondents and less than USD 100 per month for $49 \%$. In addition, over half of the respondents $(53 \%)$ answered that they had never heard about virtual wardrobe, and over $87 \%$ of them had never used or experienced the service before. This demonstrates that virtual wardrobe services represented a new technology for most of the survey respondents. Thus, the present study is appropriate to examine who the potential customers of this new service are. Specifically, the study investigates what consumer traits (PSV, FI, SRCB, and PIIT) lead to consumers' positive attitudes toward virtual wardrobes, which further result in their intention to use it.

\section{Results}

The two-step approach of structural equation modeling (SEM) [59] was utilized through LISREL to test the proposed hypotheses. Confirmatory factor analysis (CFA) was conducted first to examine the fit of the measurement model and the reliability and validity of multi-item variables; then, SEM was used to analyze the structural relationships illustrated in the proposed conceptual model.

\subsection{Evaluation of the Measurement Model}

Through the CFA, the measurement model was evaluated to examine the model fit and the relationships between the indicator variables and their respective underlying factors. Multiple fit indices were used to examine the model fit: the chi-square/degree of freedom $\left(x^{2} / \mathrm{df}\right)$, root mean squared error of approximation (RMSEA), goodness-offit index (GFI), normed fit index (NFI), non-normed fit index (NNFI), and comparative fit index (CFI). The fit indexes are included in Table 2, which shows that an acceptable fit was achieved for the measurement model: $\chi^{2} / \mathrm{df}=1.82$, RMSEA $=0.056$, GFI $=0.92$, $\mathrm{NFI}=0.93, \mathrm{NNFI}=0.96, \mathrm{CFI}=0.96$. Table 1 includes the standardized factor loadings, $\mathrm{t}$-values, composite reliability, and average variance extracted (AVE), which were used to assess the reliability and convergent validity of the measurement model. For all of the path parameter estimates in the measurement model, the $\mathrm{t}$-values were greater than 2.58; therefore, all of the path parameter estimates were statistically significant with $p<0.01$. As shown in Table 1, the AVEs ranged from 0.57 to 0.82 ; the composite reliability coefficients ranged from 0.80 to 0.93 and were above 0.70 , which is the acceptable guideline suggested by Nunnally [60], indicating support for construct reliability.

Table 2. Fit indices.

\begin{tabular}{cc}
\hline Fit Indices & Value \\
\hline Chi-Square/Degree of Freedom & 1.82 \\
Root Mean Squared Error of Approximation (RMSEA) & 0.056 \\
Normed Fit Index (NFI) & 0.93 \\
Non-Normed Fit Index (NNFI) & 0.96 \\
Comparative Fit Index (CFI) & 0.96 \\
Goodness of Fit Index (GFI) & 0.92 \\
\hline
\end{tabular}

The analysis of discriminant validity was based on a comparison of each construct's AVE value with the squared inter-construct correlations of that construct with all other constructs in the structural model [61]. In addition, the confidence interval test (the correlations between two latent constructs plus or minus two standard errors) was also employed to assess the discriminant validity. The AVEs were greater than the squared inter-construct correlations, and the confidence interval test did not include one, thus demonstrating satisfactory discriminant validity (Table 3). Therefore, the evaluation of the measurement model indicated that the measurement model was adequate for testing the proposed structural model. 
Table 3. Discriminant validity of the measurement model.

\begin{tabular}{ccccccccc}
\hline & CR & AVE & PSV & FI & SRCB & PIIT & ATT & INT \\
\hline PSV & 0.81 & 0.59 & $\mathbf{0 . 7 7}$ & 0.78 & 0.61 & 0.28 & 0.45 & 0.35 \\
FI & 0.80 & 0.57 & 0.68 & $\mathbf{0 . 7 5}$ & 0.67 & 0.32 & 0.43 & 0.38 \\
SRCB & 0.80 & 0.58 & 0.49 & 0.55 & $\mathbf{0 . 7 6}$ & 0.22 & 0.44 & 0.31 \\
PIIT & 0.83 & 0.63 & 0.14 & 0.18 & 0.08 & $\mathbf{0 . 7 9}$ & 0.56 & 0.59 \\
ATT & 0.89 & 0.73 & 0.31 & 0.29 & 0.32 & 0.44 & $\mathbf{0 . 8 5}$ & 0.84 \\
INT & 0.93 & 0.82 & 0.21 & 0.24 & 0.17 & 0.49 & 0.78 & $\mathbf{0 . 9 1}$ \\
\hline
\end{tabular}

Notes: (1) CR = composite reliability; AVE = average variance extracted. (2) PSV = personal shopping value $\mathrm{FI}=$ fashion involvement; $\mathrm{SRCB}=$ socially responsible consumer behavior; PIIT = personal innovativeness in information technology; ATT = attitude toward virtual wardrobes; INT = intention to use virtual wardrobes (3) The square roots of the AVEs are reported on the diagonal in bold; the values below the diagonal correspond to the factor correlations; the elements above the diagonal are the upper bounds of the $95 \%$ confidence intervals for the inter-factor correlations.

\subsection{The Results of Testing the Structural Model}

Figure 3 shows the results of testing the structural relationships in the model. The results of the analysis support the hypothesized relationships stated in $\mathrm{H} 3$ (socially responsible consumer behavior-attitude towards virtual wardrobes, standardized path coefficient $=0.19, t=2.43, p<0.05$ ), $\mathrm{H} 4$ (personal innovativeness in information technologyattitude toward virtual wardrobes, standardized path coefficient $=0.43, t=5.56, p<0.001$ ), and H5 (attitude toward virtual wardrobes-intention to use virtual wardrobes, standardized path coefficient $=0.79, t=13.47, p<0.001$ ), demonstrating that socially responsible consumer behavior and personal innovativeness in information technology impact young consumers' attitudes towards virtual wardrobes, which, in turn, positively and strongly affect their intentions to use virtual wardrobes. However, the relationships between personal shopping value and attitude toward virtual wardrobes (standardized path coefficient $=0.14$, $t=1.50, p>0.05)$ and between fashion involvement and attitude toward virtual wardrobes (standardized path coefficient $=0.01, t=0.08, p>0.05$ ) are insignificant, suggesting statistically insignificant impacts of personal shopping value and fashion involvement on individuals' attitude toward virtual wardrobes.

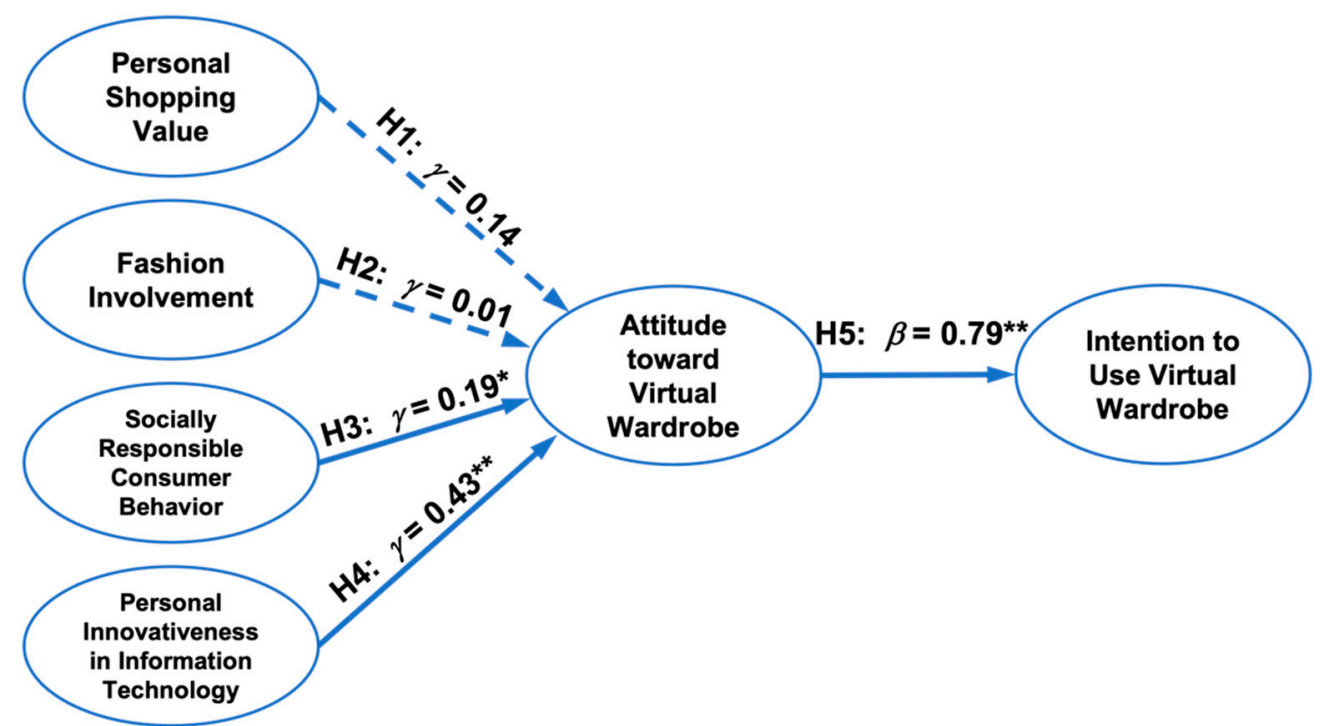

Figure 3. The results of the hypothesis testing in the structural model. (Notes: The path coefficients in the figure are standardized parameter estimates. ${ }^{*} p<0.05 ;{ }^{* *} p<0.001$. The dashed lines represent the paths with non-significant results.) 


\section{Discussion}

This study investigated the impacts of various consumer traits on consumers' behavioral intentions toward adopting a virtual wardrobe by developing and testing a virtual wardrobe adoption model that included four factors: personal shopping value, fashion involvement, socially responsible consumer behavior, and personal innovativeness in information technology. Data were collected from college students in the U.S. and analyzed using structural equation modeling. The following paragraphs provide a discussion of the results.

The study shows that young people's socially responsible consumer behavior has a positive and significant effect on their attitudes toward virtual wardrobes. Young consumers, such as Millennials and Gen Z, who actively engage in socially responsible consumer behavior are more likely to favor products or tools that help them minimize or eliminate the harmful effects of their consumption process. Apparel consumers who have a high level of socially responsible behavior tend to perceive that resource conservation and clothing consumption are related. They believe that the preservation of resources should be considered in clothing consumption and discarded clothing adds to environmental problems. They are more aware of apparel sustainability issues, and they take action in their own clothing consumption behavior by maximizing the utility of the items that are already in their wardrobes and reducing the possibility of buying unnecessary items. Technologies such as virtual wardrobes align with these consumers' beliefs and attitudes toward clothing consumption and enable these young consumers to better manage their process of consumption of fashionable clothing, thus helping them practice their socially responsible consumer behavior. Virtual wardrobes tend to amplify a consumer's identity as a socially responsible consumer; thus, they are viewed as congruent with the consumer's identity as a socially responsible consumer.

A virtual wardrobe platform supports a consumer's sustainable decision making during purchasing, as well as in pre-and post-purchase phases, via various emerging technologies such as image tracking, visual searching, and QR code recognition; thus, the entire consumer apparel consumption process tends to be sustainable. It provides information on the current closet composition to consumers so that they can figure out exactly what they own and need in their existing wardrobes in real time, preventing them from unnecessary and impulsive buying behavior. Moreover, a virtual wardrobe service informs consumers about clothing care methods, easily keeps track of each apparel item, and suggests how the existing items in the user's wardrobe can be mixed and matched to create various outfits that can express the user's own unique self-sense of personal style. Thus, a virtual wardrobe's shopping guide can suggest clothing items that are well matched with the items in a user's wardrobe and help them avoid buying duplicate products and products that do not match well with what they already have. In addition, using a virtual wardrobe leads to an increase in the utilization of the apparel items that consumers already own and helps extend the product life cycle. In this aspect, this could help in the consumer decision-making process in every stage of clothing consumption and could contribute to establishing sustainable consumption habits [62]. This important finding highlights the strong connection between sustainable consumer behavior and the use of technologies of the Internet of Things for fashion, which would have an effect on societal issues, such as sustainability $[23,63]$.

The study confirms the positive and significant effect of young consumers' personal innovativeness in information technology on their attitude toward virtual wardrobes, which is consistent with the findings of previous literature [12]. Personal innovativeness in information technology refers to people's propensity for being creative, having a positive view of technology, and being willing to be the early adopters of new technologies. Individuals with such characteristics desire to seek out new stimuli, are receptive to new ideas, and are willing to make innovative decisions. They are more positive and confident in using new technologies, and they tend to have a positive view of new technologies. The literature indicates that consumers with higher self-efficacy in technology are less worried about 
possible negative outcomes, and they focus on the pleasure and excitement in using the new technologies and view them as more useful [12]. Novelty-seeking consumers have favorable attitudes toward technology-based products, show higher intrinsic motivation to adopt such products, and are stimulated to try new ways of solving old problems [64]. Therefore, consumers with high personal innovativeness in information technology are more likely to identify and try new technologies such as virtual wardrobes. They can recognize the relative advantage of virtual wardrobes and maximize their benefits. In addition, they are more likely to perceive virtual wardrobes as useful, fun, and easier to use and to have positive attitudes toward them.

Contrary to expectations, this study shows there is no significant influence of personal shopping value on consumers' attitudes toward virtual wardrobes. Previous studies demonstrated that consumers differ in their perceived personal shopping value [32]. Personal shopping value in the behavior of apparel consumers seems to be associated with the complete apparel shopping experience, not just simply with the clothing products for which one shops [32]. A consumer's personal shopping value could prove to be an essential component of a consciousness-emotion-value model of consumer shopping experiences, and it adequately represents consumer perceptions of both the hedonic and utilitarian aspects of shopping value [32]. Thus, personal shopping value is considered as a specific and enduring internal tendency that creates a feeling of holistic view of if a shopping experience helps achieve one's clothing consumption. Moreover, in a clothing shopping context, personal shopping value highlights that a consumer's shopping behavior focuses on information processing and the expectancy-value evaluation. Shopping is helpful for a consumer to learn about current fashion styles and trends and to gain information on and inspiration for how to coordinate clothing items; thus, shopping helps consumers to find clothing that is suitable for them. Personal shopping value is subjective, developed by individuals' interactions with a shopping environment, and indicated by both shopping activities' usefulness and an appreciation of the shopping activities [32]. This study's surprising and interesting finding indicates that attitude toward virtual wardrobes appears to be irrelevant to a consumer's personal shopping value. One possible explanation could be that consumers with high levels of personal shopping value tend to enjoy the physical in-store shopping trips, value the inherent personal satisfaction in the ritual of a physical shopping trip, and are used to making unplanned purchase decisions or impulse buying. Thus, they just enjoy shopping for new items without having the habit of considering existing items in their wardrobes. Another reason might be that they update their wardrobes by purchasing many fast-fashion products and discard them quite frequently. They may not have the need to use virtual wardrobes to help them organize their wardrobes.

Unexpectedly, the proposed relationship between fashion involvement and consumers' attitude toward virtual wardrobes was not supported, which is revealing and surprising. Fashion involvement, defined as an individual's interest in and attachment to fashion products, is positively associated with an interest in following fashion trends, gathering fashion product information, and gaining a greater sensitivity to differences among fashion products and brands $[36,57]$. The literature maintains that consumers with a high degree of fashion involvement are often fashion innovators or opinion leaders among their peers, and they use fashion consumption to enhance their sense of self $[36,45]$. One plausible explanation for the insignificant relationship between fashion involvement and attitude toward virtual wardrobes could be that the survey respondents were college students. Many of them were the consumers of low-priced fast fashion and were interested in acquiring trendy styles for instant satisfaction. They may not have the need for using virtual wardrobes to help them create various styles of outfits for various occasions, as students on campus mainly have simple and casual clothing styles, or they were not required to dress up during the COVID-19 pandemic. Thus, due to the lack of opportunities to use virtual wardrobes, they may not be able to perceive the benefits of using them. Another reason may be related to the inventory process for virtual wardrobes. Consumers may perceive registering and creating a digital wardrobe as massively tedious, energy- 
consuming, and time-consuming, which can be an obstacle for using such apps. In addition, as managing and organizing a wardrobe is a very personal thing that varies from person to person, consumers may not trust that virtual wardrobes could truly bring functional benefits in this initial stage. It is still a new concept, and most consumers have not tried it so far.

Consistently with Fishbein's [14] attitude theory and previous research on technology adoption [12,64], a consumer's attitude toward virtual wardrobes is a strong determinant of their behavioral intention to use them. This study demonstrates that attitude is one of the key factors in stimulating consumers' intentions to use virtual wardrobes, and the attitude-intention link is essential in the context of virtual wardrobe adoption.

\section{Conclusions}

This study is novel, as it investigates what consumer characteristics motivate consumers to use a virtual wardrobe and proposes marketing strategies to address these behaviors. The study's findings offer valuable theoretical and managerial implications for researchers and industry practitioners. Innovative and interactive technologies are rapidly employed in the fashion retail market to enhance fashion consumers' experience in the full process of shopping, purchasing, and post-purchase decisions [21]. However, majority of the technologies focus mainly on the purchasing phase. The present study focuses on virtual wardrobes, which are technological platforms that allow for sustainable consumer decision making throughout the whole consumption process, including the pre-purchase, purchase, and post-purchase phases. Technologies are evolving as along with apparel consumption behavior, leading to an evolution of the management of consumers' apparel consumption. Consumers demand new experiences in apparel consumption with the help of new applications of technology. Thus, this calls for more research on the role of digital technologies in improving consumers' clothing consumption experience.

Theoretically reflecting new consumer technology trends, the present study identified the effects of consumer traits on attitudes and use intentions toward virtual wardrobes. There is little research on consumer behavior related to virtual wardrobes, and previous literature on smart closets centered on the application of the technology acceptance model by examining the impacts of perceived ease of use and perceived usefulness on consumers' adoption of smart closets. This study contributes to the virtual wardrobe literature by integrating personal shopping value, fashion involvement, socially responsible consumer behavior, and personal innovativeness in information technology into an attitude-intention model of virtual wardrobes. By surveying a group of U.S. college students, this study advances the understanding of young U.S. consumers' attitudes and use intentions in relation to virtual wardrobes. This study provides evidence that personal innovativeness in information technology and socially responsible consumer behavior are the two main drivers of positive attitudes toward virtual wardrobes, which further leads to the intention to use virtual wardrobes. This study's findings contribute to the literature by offering convincing evidence of the positive linkage between sustainable consumer behavior and the adoption of digital fashion $[22,23,63]$. The growing interest in digital fashion research has been accelerated by the recent COVID-19 pandemic [63]. In the post-COVID era, digital fashion will provide opportunities for apparel consumers to embrace sustainability [23,63].

Practically, this study offers a solid basis for developing favorable consumer attitudes toward virtual wardrobes and causing their adoption of virtual wardrobes. The study offers some valuable practical insights about the effects of consumer traits on virtual wardrobe adoption. It can be said that consumer traits are important and can help marketers of virtual wardrobes in developing effective and stimulating marketing strategies to obtain every possible opportunity available in the fashion retail market. The understanding of these variables helps virtual wardrobe technology developers, marketers, and fashion brands to collectively work together to contribute to apparel sustainability issues and efficiently target their potential customers. The study's findings imply that virtual wardrobe marketers should focus on promoting the innovative and sustainable aspects of using 
their technology-based virtual wardrobes so consumers can feel that the use of virtual wardrobes aligns with their personal characteristics. This strategy is congruent with the characteristics of virtual wardrobe users, demonstrating a natural promotional fit because individuals with a high degree of personal innovativeness in information technology and socially responsible consumer behavior have a strong tendency to adopt such products. To increase the adoption intention, marketers of virtual wardrobes should highlight social responsibility and technological innovation in their product and service promotions. For example, marketing advertisements of virtual wardrobes should not only highlight how innovative the technology is, but also promote its potential in impacting consumers' clothing consumption, such as by improving the usage of clothing items, reducing clothing waste, and protecting natural resources and the environment.

Marketers of virtual wardrobes should target young consumers, such as the Millennials and members of Generation Z involved in this study, who are interested in both new technologies and sustainable lifestyles. These groups of consumers are more willing to embrace new ideas and want new experiences, and they are more technology savvy and willing to try new technologies and services in their lives. Considering the escalation of sustainable lifestyles and technological innovations in more and more consumers' lives, adopting new technologies such as a virtual wardrobe service to enhance the sustainability of their lifestyles is a perfect way to be early innovation adopters, fashion leaders, and sustainable consumers at the same time. Marketers and technology companies should develop appealing virtual wardrobe platforms to tap into this emergent consumer market, keeping them inspired and entertained. They should consider how to provide the enjoyable and satisfactory experiences that consumers usually gain when doing traditional in-store shopping.

Product developers and software engineers should utilize these insights to develop innovative features and improve the functions of virtual wardrobes. Utilizing consumer insights in the product development process is critical for enhancing the functionality of smart technologies, such as virtual wardrobes. To promote the diffusion of virtual wardrobe applications to more consumers, it is necessary to think about how to persuade consumers to try this new service despite their naturally lower levels of personal innovativeness. For example, before convincing consumers of the utilitarian value of a virtual wardrobe, virtual wardrobe providers could emphasize its fashion enjoyment to attract consumers, and it may be a good idea to encourage trial experiences to make consumers familiar with the virtual wardrobe. Furthermore, to attract highly involved fashion consumers, it is important to design virtual wardrobe platforms that offer style and shopping suggestions and to underline fashion information and interactive shopping features at the same time. The development of an interactive, innovative, user- and experience-friendly interface is critical for attracting more customers. For example, virtual wardrobe developers may find a solution to systematically streamlining consumer decision making in the pre-purchase, purchase, and post-purchases phases and integrating various digital fashion aspects, such as in-depth fashion trend information and fashion brand/product information, direct inapp purchases, wish lists, promotion alerts, price comparisons, and avatars with which the user can create different outfits and experiment with new fashion styles [23,63]. More functions would also be desirable, such as statistics on cost per wear and tracking features, such as past wear records (where and when one wore certain garments), the frequency of wearing a particular garment, a calendar feature, etc. In addition, virtual wardrobe developers need to set up a competent, experienced, and knowledgeable marketing team to promote their virtual wardrobe products and services.

Finally, retailers can collaborate with virtual wardrobe providers to have their products included in the databases to be easily accessed by virtual wardrobe users. Virtual wardrobe apps could be promoted by a leading or well-recognized fashion retailer to drive customer engagement, thus complementing the digital communication channels that the fashion retailer already has. Retailers should recognize the new technologies' potential to engage 
their consumers, create new experiences, and generate added value for both consumers and fashion brands.

Virtual wardrobe applications are still in an initial stage of development and need to keep optimizing their functions. Apparel consumers are becoming more sophisticated in terms of their need for personalization, uniqueness, and sustainable values. Technology companies, the apparel manufacturing industry, and fashion retailers should adapt to the fast-changing demands of fashion consumers, sustainable lifestyle trends, and new virtual technology applications.

There are several limitations that offer opportunities for future research. First, this study revealed young U.S. consumers' perspectives on virtual wardrobes. Future studies should explore the model of this study in a wider setting in terms of age groups, such as Generation X. In addition, future cross-cultural studies may provide more insights into the perceptions of young consumers towards virtual wardrobes, and future cross-cultural comparisons would show the differences between U.S. consumers and consumers in other countries. Second, this study used a convenience sample by surveying college students in Apparel Design and Retail Merchandising in three U.S. universities. Thus, due to this limitation in sampling, caution should be used when interpreting the results of this study. Further studies should consider surveying a random sample of college students. Third, this study focused on the roles of four consumer traits in attitude and adoption intention toward virtual wardrobes. Future studies could explore more factors, such as subjective norms. In addition, virtual wardrobe design and interface features may impact virtual wardrobe adoption. Finally, this study employed a survey-based quantitative research approach to achieve the research objectives. Future studies may employ a qualitative approach to investigate the factors impacting consumers' adoption of virtual wardrobes and their expectations.

Author Contributions: Conceptualization, H.B.; Data curation, H.B.; Formal analysis, J.S.; Investigation, H.B. and J.S.; Methodology, H.B. and J.S.; Project administration, H.B.; Resources, H.B. and J.S.; Validation, J.S.; Visualization, H.B. and J.S.; Writing—original draft, H.B. and J.S.; Writing—review and editing, H.B. and J.S. All authors have read and agreed to the published version of the manuscript.

Funding: The APC for this research was funded by Jin Su's grant from the Open Access Publishing Support Fund co-sponsored by the University Libraries and the Office of Research and Engagement at the University of North Carolina at Greensboro, USA.

Institutional Review Board Statement: Ethical review and approval were waived for this study because the research involved no more than minimal risk to subjects.

Informed Consent Statement: Informed consent was waived due to the fact that students' participation was voluntary and personal identification was not shared.

Data Availability Statement: The data are not publicly available, as respondents were guaranteed confidentiality and anonymity in this study.

Conflicts of Interest: The authors declare no conflict of interest.

\section{References}

1. Gwozdz, W.; Steensen Nielsen, K.; Müller, T. An Environmental Perspective on Clothing Consumption: Consumer Segments and Their Behavioral Patterns. Sustainability 2017, 9, 762. [CrossRef]

2. Closetmaid. Survey: Women's Closets Are Full to the Brim. 2020. Available online: https://blog.closetmaid.com/2016/05/fullto-the-brim (accessed on 22 November 2021).

3. Tighe, D. Average Number of Clothing Products Women in the United States Have in Their Wardrobe and Don't Wear, as of January 2017. Available online: https://www.statista.com/statistics/789475/clothes-women-don-t-wear/ (accessed on 22 November 2021).

4. Bye, E.; McKinney, E. Sizing up the Wardrobe-Why We Keep Clothes That Do Not Fit. Fash. Theory 2007, 11, 483-498. [CrossRef]

5. Fukuda, M.; Nakatani, Y. Clothes recommend themselves: A new approach to a fashion coordinate support system. In Proceedings of the World Congress on Engineering and Computer Science, San Francisco, CA, USA, 19-21 October 2011.

6. Goh, K.N.; Chen, Y.Y.; Lin, E.S. Developing a smart wardrobe system. In Proceedings of the 2011 IEEE Consumer Communications and Networking Conference (CCNC), Las Vegas, NV, USA, 9-12 January 2011; pp. 303-307. 
7. Al-Omar, N.N.; Al-Rashed, N.M.; Al-Fantoukh, H.I.; Al-Osaimi, R.M.; Al-Dayel, A.-H.A.; Mostefai, S. The design and development of a web-based virtual closet: The smart closet project. J. Adv. Manag. Sci. 2013, 1, 124-128. [CrossRef]

8. Li, Y.; Hu, W. The Conceptual Design of "Smart Closet" Fashion Consultant Expert System. Int. J. Bus. Soc. Sci. 2014, 5, 149-154.

9. Rode, J.A.; Magee, R.; Sebastian, M.; Black, A.; Yudell, R.; Gibran, A.; McDonald, N.; Zimmerman, J. Rethinking the smart closet as an opportunity to enhance the social currency of clothing. In Proceedings of the 2012 ACM Conference on Ubiquitous Computing, Pittsburgh, PA, USA, 5-8 September 2012; pp. 183-192.

10. Etebari, D. Intelligent Wardrobe: Using Mobile Devices, Recommender Systems and Social Networks to Advise on Clothing Choice. Master's Thesis, University of Birmingham, Birmingham, UK, 2014.

11. Han, W. Investigation of Chinese Consumers' Adoption Intention toward E-Wardrobe: A Psychological Need and Motivational Approach. Master's Thesis, North Carolina State University, Raleigh, NC, USA, 2021.

12. Perry, A. Consumers' acceptance of smart virtual closets. J. Retail. Consum. Serv. 2016, 33, 171-177. [CrossRef]

13. Shaw, D.; Duffy, K. Save Your Wardrobe: Digitalising Sustainable Consumption: Further Insights; University of Glasgow: Glasgow, $\mathrm{UK}, 2020$.

14. Fishbein, M.; Ajzen, I. Belief, Attitude, Intention, and Behavior: An Introduction to Theory and Research; Addison-Wesley: Boston, MA, USA, 1975.

15. Ajzen, I.; Fishbein, M. Understanding Attitudes and Predicting Social Behavior; Prentice-Hall: Englewood Cliffs, NJ, USA, 1980.

16. Paul, A.P. Consumer acceptance of electronic commerce: Integrating trust and risk with the Technology Acceptance Model. Int. J. Electron. Commer. 2003, 7, 101-134. [CrossRef]

17. Taylor, S.; Todd, P.A. Understanding Information Technology Usage: A Test of Competing Models. Inf. Syst. Res. 1995, 6, 144-176. [CrossRef]

18. Klobas, J.E. Beyond information quality: Fitness for purpose and electronic information resource use. J. Inf. Sci. 1995, 21, 95-114. [CrossRef]

19. Rondan-Cataluña, F.J.; Arenas-Gaitán, J.; Ramírez-Correa, P.E. A comparison of the different versions of popular technology acceptance models. Kybernetes 2015, 44, 788-805. [CrossRef]

20. Ho, C.-W.; Wang, Y.-B.; Yen, N.Y. Does environmental sustainability play a role in the adoption of smart card technology at universities in Taiwan: An integration of TAM and TRA. Sustainability 2015, 7, 10994-11009. [CrossRef]

21. Shankar, V.; Kalyanam, K.; Setia, P.; Golmohammadi, A.; Tirunillai, S.; Douglass, T.; Hennessey, J.; Bull, J.S.; Waddoups, R. How Technology Is Changing Retail. J. Retail. 2021, 97, 13-27. [CrossRef]

22. Vătămănescu, E.-M.; Dabija, D.-C.; Gazzola, P.; Cegarro-Navarro, J.G.; Buzzi, T. Before and after the outbreak of COVID-19: Linking fashion companies' corporate social responsibility approach to consumers' demand for sustainable products. J. Clean. Prod. 2021, 321, 128945. [CrossRef]

23. Noris, A.; Nobile, T.H.; Kalbaska, N.; Cantoni, L. Digital Fashion: A systematic literature review. A perspective on marketing and communication. J. Glob. Fash. Mark. 2021, 12, 32-46. [CrossRef]

24. Wan, D. Magic Wardrobe: Situated Shopping from Your Own Bedroom. Pers. Technol. 2000, 4, 234-237. [CrossRef]

25. Peifeng, H.; Yuzhe, C.; Jingping, S.; Zhaomu, H. Smart Wardrobe System Based on Android Platform. In Proceedings of the 2016 IEEE International Conference on Cloud Computing and Big Data Analysis (ICCCBDA), Chendu, China, 5-7 July 2016; pp. 279-285.

26. Dalal, J.; Dalmia, A.; Desai, J.; Amrutia, H. Smart Wardrobe-IoT Based Application. IRJET 2019, 6, 3699-3702.

27. Vermeir, I.; Verbeke, W. Sustainable Food Consumption: Exploring the Consumer "Attitude-Behavioral Intention" Gap. J. Agric. Environ. Ethics. 2006, 19, 169-194. [CrossRef]

28. Zeithaml, V.A. Consumer perceptions of price, quality, and value: A means-end model and synthesis of evidence. J. Mark. 1988, 52, 2-22. [CrossRef]

29. Holbrook, M.B. Consumer Value: A Framework for Analysis and Research; Routledge: New York, NY, USA, 1999.

30. Chen, Z.; Dubinsky, A.J. A conceptual model of perceived customer value in e-commerce: A preliminary investigation. Psychol. Mark. 2003, 20, 323-347. [CrossRef]

31. Mathwick, C.; Malhotra, N.; Rigdon, E. Experiential value: Conceptualization, measurement and application in the catalog and Internet shopping environment. J. Retail. 2001, 77, 39-56. [CrossRef]

32. Babin, B.J.; Darden, W.R.; Griffin, M. Work and/or fun: Measuring hedonic and utilitarian shopping value. J. Consum. Res. 1994, 20, 644-656. [CrossRef]

33. Davis, L.; Hodges, N. Consumer shopping value: An investigation of shopping trip value, in-store shopping value and retail format. J. Retail. Consum. Serv. 2012, 19, 229-239. [CrossRef]

34. Batra, R.; Ahtola, O.T. Measuring the hedonic and utilitarian sources of consumer attitudes. Market. Lett. 1991, 2, 159-170. [CrossRef]

35. Meilhan, D. Customer Value Co-Creation Behavior in the Online Platform Economy. J. Self-Gov. Manag. Econ. 2019, 7, 19-24. [CrossRef]

36. O'Cass, A. Fashion clothing consumption: Antecedents and consequences of fashion clothing involvement. Eur. J. Mark. 2004, 38, 869-882. [CrossRef]

37. Zhang, B.; Kim, J.-H. Luxury fashion consumption in China: Factors affecting attitude and purchase intent. J. Retail. Consum. Serv. 2013, 20, 68-79. [CrossRef] 
38. Kim, H. The Impact of Body Image Self-Discrepancy on Body Dissatisfaction, Fashion Involvement, Concerns with Fit and Size of Garments, and Loyalty Intentions in Online Apparel Shopping. Ph.D. Thesis, Iowa State University, Ann Arbor, MI, USA, 2008.

39. Sproles, G.B.; King, C.W. The Consumer Fashion Change Agent: A Theoretical Conceptualization and Empirical Identification; Institute for Research in the Behavioral, Economic, and Management Sciences; Purdue University: West Lafayette, IN, USA, 1973.

40. Chang, C. Message framing and interpersonal orientation at cultural and individual levels. Int. J. Advert. 2010, $29,765-794$. [CrossRef]

41. Liang, Y.; Lee, S.-H.; Workman, J.E. Implementation of artificial intelligence in fashion: Are consumers ready? Cloth. Text. Res. J. 2020, 38, 3-18. [CrossRef]

42. Celik, H.; Kocaman, R. Roles of self-monitoring, fashion involvement and technology readiness in an individual's propensity to use mobile shopping. J. Syst. Inf. Technol. 2017, 19, 166-182. [CrossRef]

43. Ríos-Rodríguez, M.L.; Salgado-Cacho, J.M.; Moreno-Jiménez, P. What impacts socially responsible consumption? Sustainability 2021, 13, 4258. [CrossRef]

44. Roberts, J.A. Profiling levels of socially responsible consumer behavior: A cluster analytic approach and its implications for marketing. J. Mark. Theory Pract. 1995, 3, 97-117. [CrossRef]

45. Mohr, L.A.; Webb, D.J.; Harris, K.E. Do consumers expect companies to be socially responsible? The impact of corporate social responsibility on buying behavior. J. Consum. Aff. 2001, 35, 45-72. [CrossRef]

46. Winakor, G. The process of clothing consumption. J. Home Econ. 1969, 61, 629-634.

47. Ha-Brookshire, J.E.; Hodges, N.N. Socially responsible consumer behavior?: Exploring used clothing donation behavior. Cloth. Text. Res. J. 2009, 27, 179-196. [CrossRef]

48. Fagan, M.; Kilmon, C.; Pandey, V. Exploring the adoption of a virtual reality simulation. Campus-Wide Inf. Syst. 2012, 29, 117-127. [CrossRef]

49. Lu, J. Are personal innovativeness and social influence critical to continue with mobile commerce? Internet Res. 2014, 24, 134-159. [CrossRef]

50. Rogers, E.M. Diffusion of Innovations, 5th ed.; Free Press: New York, NY, USA, 2003.

51. Agarwal, R.; Prasad, J. A conceptual and operational Definition of personal innovativeness in the domain of information technology. Inf. Syst. Res. 1998, 9, 204-215. [CrossRef]

52. Lu, J.; Yao, J.E.; Yu, C.-S. Personal innovativeness, social influences and adoption of wireless Internet services via mobile technology. J. Strateg. Inf. Syst. 2005, 14, 245-268. [CrossRef]

53. Ajzen, I.; Fishbein, M. Attitude-behavior relations: A theoretical analysis and review of empirical research. Psychol. Bull. 1977, 84, 888-918. [CrossRef]

54. Watson, R.; Popescu, G.H. Will the COVID-19 Pandemic Lead to Long-Term Consumer Perceptions, Behavioral Intentions, and Acquisition Decisions? Econ. Manag. Financ. Mark. 2021, 16, 70-83. [CrossRef]

55. Rydell, L.; Kučera, J. Cognitive Attitudes, Behavioral Choices, and Purchasing Habits during the COVID-19 Pandemic. J. Self-Gov. Manag. Econ. 2021, 9, 35-47. [CrossRef]

56. Ajzen, I.; Fishbein, M. The influence of attitudes on behavior. In The Handbook of Attitudes; Albarracín, B.T.J.D., Zanna, M.P., Eds.; Lawrence Erlbaum Associates: Mahwah, NJ, USA, 2005; pp. 173-221.

57. O'Cass, A. An assessment of consumers product, purchase decision, advertising and consumption involvement in fashion clothing. J. Econ. Psychol. 2000, 21, 545-576. [CrossRef]

58. Stephens, S.H. Attitudes toward Socially Responsible Consumption: Development and Validation of A Scale and Investigation of Relationships to Clothing Acquisition and Discard Behaviors. Ph.D. Thesis, Virginia Polytechnic Institute and State University, Ann Arbor, MI, USA, 1985.

59. Hair, J.F.; Black, W.C.; Babin, B.J.; Anderson, R.E. Multivariate Data Analysis, 8th ed.; Cengage Learning EMEA: Hampshire, UK, 2019.

60. Nunnally, J.C. Psychometric Theory, 2nd ed.; McGraw-Hill: New York, NY, USA, 1978.

61. Fornell, C.; Larcker, D.F. Structural equation models with unobservable variables and measurement error: Algebra and statistics. J. Mark. Res. 1981, 18, 382-388. [CrossRef]

62. Bocken, N.M.P.; Short, S.W.; Rana, P.; Evans, S. A literature and practice review to develop sustainable business model archetypes. J. Clean. Prod. 2014, 65, 42-56. [CrossRef]

63. Nobile, T.H.; Noris, A.; Kalbaska, N.; Cantoni, L. A review of digital fashion research: Before and beyond communication and marketing. Int. J. Fash. Des. Technol. Educ. 2021, 14, 293-301. [CrossRef]

64. Dabholkar, P.A.; Bagozzi, R.P. An attitudinal model of technology-based self-service: Moderating effects of consumer traits and situational factors. J. Acad. Mark. Sci. 2002, 30, 184-201. [CrossRef] 